\title{
The Construction of Innovation Education Mode Based on Engineering Education
}

\author{
Guanhao $^{1, a}$, Lanjian $^{2, b}$ \\ ${ }^{1}$ Dalian City, Liaoning Province,China \\ ${ }^{2}$ Dalian City, Liaoning Province,China \\ aemail:ghdldx@sina.com
}

Keywords: Engineering Education Innovation Mode Construction

\begin{abstract}
As engineering education faces the responsibility to cultivate the demanding innovative talents in the 21st century, it must undertake corresponding reform of education mode. This article analyses the main problem of the present engineering education from the connotation and characteristics of engineering education, putting forward that cultivating innovative talents need to update educational concept, combining the actual situation of Dalian University and other colleges and universities, putting forward the exploration and construction of the innovative education model based on engineering education thoughts and ideas.
\end{abstract}

\section{Introduction}

The so-called innovative education refers to take various educational methods to cultivate students' innovative quality and improve their innovative ability on the basis of quality education and students' individual development, ultimately adapting to cultivate the demanding 21 century innovative talents as the goal of the higher education model . The construction of engineering innovation education mode is to treat innovative education as a complete system engineering, under the guidance of quality education thoughts, adhere to combine the professional education with basic education, theory education with social practice and professional technological training with humanistic spirit shaping, doing some profound changes on the school educational goal curriculum system, educational methods and means, and the culture of campus, which form an educational environment and atmosphere that have the innovative features both in process and outcome overall, and form gradually an educational way with regular behavior feature in the constant practice which not only stress on the storage of knowledge, but also the incremental and flow, even the innovation, dissemination and use of knowledge.

\section{Engineering education and its characteristics}

Engineering is a practice to apply to the scientific theory, technology and practice experience to transform the nature and objective world. Engineering education is to take science and technology as the main discipline. It is a special education whose target is develop these kind of engineers who can convert science and technology into productive forces. Modern engineering education should not only consider the education attribute, according to the general engineering technical talents' development discipline organizing teaching, but also consider its engineering properties, in big science, the idea of large scale engineering perspective doing some essential education for future engineer about the scientific method and creative thinking, science and technology principle, economic management and marketing, ecological and environmental protection and law.

The main characteristics of modern engineering:(1) Scientific. Engineering development more and more depends on the development of science and technology and application, especially the application of new and high technology is the key of Engineering innovation. So the talents cultivated by engineering education not only need to have profound professional knowledge, but also have higher science and technology literacy and profound theoretical basis, in order to solve the engineering scientific and technical problems in practice.

(2). Social. The realization to the nation, ethnic, society and lifestyle becomes more and more a 
problem that engineering design must consider. Engineering has become a comprehensive social activity, modern engineering has social value, so the talents cultivated by engineering education not only understand technology but also have more knowledge of the society, such as economic, environmental, ecological and cultural knowledge.

(3). Innovative. Science is the foundation of the world, scientists research the present world, and engineers create the world which is not existed. So creation is the essence of engineering. Engineering education should cultivate students' innovative thinking and innovative ability so that they can creatively apply to the knowledge of science and technology into engineering practice to undertake new products' design work.

(4). Practical. As the project definition can be seen clearly that engineering is practical, and it is a kind of purposeful activity, reflected in the development, design and manufacture of processing and other manufacturing activities. Without practice, science and technology can not be transformed into productivity, can be converted into defining products and project, so practice is the core of the project.

(5).Complex. The complexity of the project is shown not only in the engineering activities on multidisciplinary knowledge, the comprehensive application of technology, but also in many modern works which must be coordinated from various social interests, objective conditions and so on. Any project is a comprehensive. At the same time, the engineering society is also increasing, which is not only the technical and economic issues, but also the political, cultural, environmental and social problems. The project's comprehension requires students cultivated by engineering education with engineering background and economic, management, financial, trade and other interdisciplinary knowledge, having strong decision, organization, coordination and management ability.

The characteristics of modern engineering, especially the nature of innovation determine innovative education plays an important role in engineering education. Under the market economy system, in order to make modern enterprises be in an invincible position in the fierce competition, it largely relies on innovative consciousness and innovation ability of engineering and technical personnel, using new materials, new technics, new technology, development and production of new products. Therefore, the current engineering education is one of the important tasks to change the educational concept and the implementation of innovative education.

\section{The current main problems in Engineering Education.}

The overspecialization of engineering education lead to students' poor ability of adaptation and creativity.Although in last few years the relative majors were adjusted and compressed, but there are many colleges which have not keep up with the pace of professional adjustment, curriculum pattern is too single, and still emphasizing professional education result in students' knowledge is too narrow to adapt to the modern engineering practice disciplines permeate each other, and the highly integrated trend of demand to composite talents, the weak ability to adapt to the environment.

Theory divorced from practice.Students generally lack the training of engineering practice, practice ability, and practical ability. In recent years, although the engineering colleges has repeatedly called on to strengthen the practice teaching link, but due to various restricted conditions, the proportion of students' practice teaching link constitutes the entire teaching link is still lower. Students rarely participate in product design, machinery manufacture which is social practice activity of the front line. After graduation, the students' design ability is generally low, poor ability in solving practical engineering problems. Sometimes in the face of some larger projects will be at a loss what to do, lack of flexibility and innovation ability.

The humanity's quality is not high, and it is lack of the cultural deposits of raising innovative spirit and innovative ability.In recent years, the engineering problem has become more and more complex and continued to go beyond the purely scientific and technical problems. Engineering are increasingly associated with society, politics, economy, structure, ecology, ethics but the current college graduates lack knowledge background and humanistic quality, and less oral and written communication skills, interpersonal communication and organizing ability, which cannot adapt to 
the requirement of modern engineering and is difficult to bear modern project management tasks.

The type of inheritance education suppresses students' enthusiasm for innovation.Inheritance of education refers to the higher education of our country in the long form of the traditional classroom teaching mode. It emphasizes the importance of" three centers": take the classroom as the center, take the teacher as the center, take the books as the center. Neglect to mobilize students' learning initiative and creativity, and take students as passive consumers. School education is a kind of rush cramming method of teaching, rarely using heuristic, discussion and learning and other teaching methods, which causes the students passive learning, rote learning, exam-targeted, less innovation awareness.

\section{Exploration and construction of engineering education innovation mode .}

As mentioned before, innovative education is a systematic project, which covers the whole teaching system for undergraduates. Therefore, the innovation education should be a full range of teaching process, and the innovation education mode should also be a global concept.

Reform the foundation of the teaching system and innovative education .Innovation education is throughout the whole process of undergraduate teaching. Classroom teaching is not only an important link of the innovation education, but also is the next step in realizing students' innovative thinking, and the foundation of innovative design . Therefore, in the teaching plan, the ideas of innovation education should be fully considered, according to the development of industrial technology and the needs of society reasonably adjusting the teaching plan, basic knowledge must be solid, at the same time, to increase the innovation theory curriculum, highlighting the cultivation of students' innovative consciousness in the teaching, and development, design of teaching should account for a certain proportion.

The practical teaching is the key to creative education."Innovation is always developed in solving problem, solving problem is the innovation of the soil". Not necessarily all problem solving contains innovation, but there is no doubt that creativity contains problem solving, " the necessary way of problem solving is practice", through the practice, students can better absorb the knowledge in class and books, keen to find problems, through ceaseless practice to find a solution to the problem, through practice to verify whether the problem is solved. Engineering colleges, because of their professional training needs for students, , has a solid foundation and long-term accumulation of advantage and experience to provide practice opportunities, practice equipment, practice environment for students, but cannot stand still, the link of practice should be constant strengthen, so as to achieve the ultimate goal of cultivating innovative talents. Therefore, the implementation of innovative education is an important practical teaching, especially for engineering colleges. Therefore, the construction of practice teaching system is an important link.

Practice quality education, and establish and perfect tutorial system. In the undergraduate tutorial system has been recognized by many colleges, there is no doubt that it plays a very important role in the implementation of innovative education . Undergraduate tutor for students specific learning, life, thinking and provide advice and guidance to undergraduate education, from the bulk of education to personality education. In particular the mentors through instruction and demonstration cultivate students' innovative consciousness and professional interest, for the students as soon as possible to enter the laboratory, exposure to high levels of scientific research to create good conditions.

College Students' Studio is a form of innovation quality cultivation for many colleges in recent years, students in the studio can combine with the learned knowledge, according to their own interests and their project to participate in teachers' engineering innovation project, whose works can participate in various competitions or directly serve the society. At the same time, the school take it as a platform, through the implementation of college students a series of innovative quality training and organizing students to develop innovation activity, exploration and innovation education of innovation education, construction of ecological environment construction, develop innovative talent training mode research, practice has proved, in the establishment of the studio, is to cultivate students' innovation consciousness and ability. An excellent model, and achieved good results. 
Carry out social practice and develop the students to know the society from a new perspective.Social practice and the practice have something in common, but the latter relative focus on professional training, the range is not wider and the role is not more comprehensive than the former. In fact, the social practice is an important link of innovation education, innovation education is a good auxiliary means.For one thing, a social practice can make students understand the society, know national culture, cultivate the dedication and sense of social responsibility, and learn to deal with various relations and interpersonal relations, also help to develop the students' comprehensive quality. For another thing, the engineering college students after graduation, mostly to businesses, the modern enterprise technology updates fast, management more scientific, students enrolled in a university period to the enterprise to carry on the social practice, which is the most direct and effective method to adapt to the society. To make social practice really plays its due role, they must be carefully designed, taking part in social practice activities, and the establishment of mechanisms to ensure their normal operation.

As a matter of fact, the cultivation of innovative talents is for our whole education system innovation, including the concept of innovation, method innovation and the innovation of education environment and so on. This is a systematic project, which needs long-term unremittingly efforts and constant exploration and practice. On the cultivation of innovative talents in engineering colleges have their own advantages, such as industrial status, practice opportunities, also have their own weakness, as in professional settings on a single cause humanistic culture atmosphere weakness. Engineering colleges should fully take its advantages, emphasize the weak link, establish and perfect the system of innovative talents. Thus, for society, for the country to cultivate innovative talents from all walks of life, which becomes the forever prosperous origin of our nation.

\section{References}

[1]" The Research of Higher Education Massification" higher education association of Liaoning province, Shenyang University Press, July in 2003.

[2]"Higher Education Reform in The Face of WTO" edited by Liu Guorui, Liu Wanfang, Xu Zhizhong, Liaoning people's press, April in 2002. 